\title{
A escrita em questão: fuga ou invenção do cotidiano'
}

Dominique Morizot

Doutora em Ciências da Informação e da Comunicação,

professora no Departamento de Ergologia da Universidade de Provence, França.

\section{HÁ JOGO NA LÍNGUA}

"Imutavelmente estruturado(a) e no entanto infinitamente renovável": em O Prazer do Texto, Roland Barthes atribui à língua essas duas qualidades. Ora, a renovação da língua, assegurada por aqueles que a falam, exerce influência, ao mesmo tempo, sobre o que é denominado desde Chomsky, distinguindo-as: competência e performance. Entre estrutura e renovação, entre competência e performance abre-se um espaço: o do jogo, "o jogo imprevisível, surpreendente, singular, com e contra os signos", que constitui, como afirma Julia Kristeva, "a única liberdade dada ao ser falante". Esse espaço funda uma instância do sujeito, necessária ao seu desdobramento e à sua elaboração.

A educação tem como missão o ensino da competência e como fim uma apropriação coletiva da língua e de suas leis. Este ensino, que se estabeleceu como disciplina a partir de 1882, leva o mesmo nome da língua: o francês. A fala é aprendida na audição do outro e na repetição, ao passo que a escrita, lugar da norma e da regra, presta-se melhor que o oral a muitos controles. O francês apóia-se prioritariamente sobre a aprendizagem da escrita. É lá que reina sua existência moral, e que o uso é soberano. Por isso e principalmente: a dúvida sobre a existência do sujeito pode ser evocada, já que o outro não é visto na escrita. Nós só saberíamos efetivamente escrever a aquele que não está aqui, e cuja ausência torna mais imperioso o emprego das normas e dos códigos próprios à escrita.

Este ensino tem por objetivo fazer com que as pessoas que lhe são confiadas obedeçam e reconheçam a instituição-língua. Se o esforço despendido é exorbitante, o mesmo se justifica, pois é uma questão de identidade, de vínculo.

A apropriação da língua representa a passagem para um estado que não poderá, entretanto, ser considerado como o estado de um sujeito ${ }^{4}$ se o percurso que o tornou possível não integra o trabalho da performance.

Ora, a educação parece não ficar à vontade quando se encarrega do ensino da performance (o qual trata de realizar, e não de analisar em corpus previamente constituído). Isso, devido essencialmente a duas razões que se articulam entre

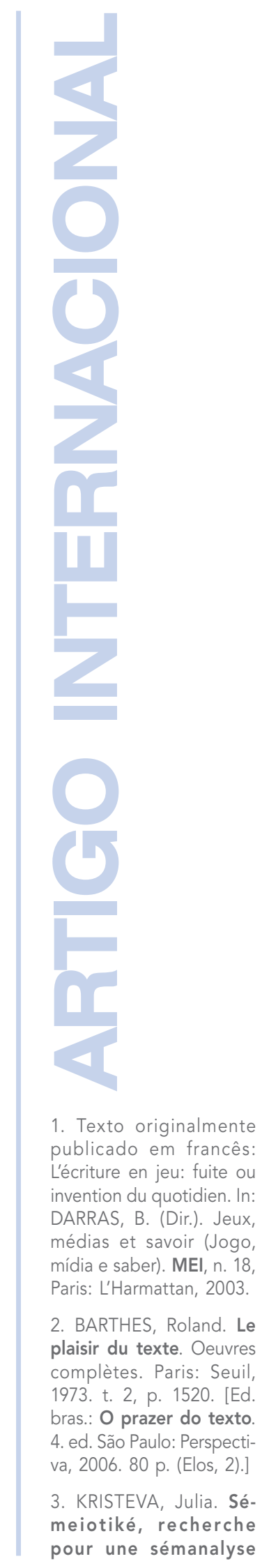


(Semiótica, busca por uma semanálise). Paris: Seuil 1969. p. 5.

4. O sujeito evocado aqui remete ao conceito de sujeito proposto por TOURAINE, Alain. Critique de la modernité (Crítica da modernidade). Paris: Fayard, 1992. p. 5.

5. RANCIÈRE, Jacques. Le partage du sensible, esthétique et politique. Paris: La Fabrique, 2000. p. 70. [Ed. bras.: A partiIha do sensível: estética e política. São Paulo: Exo Experimental/Editora 34 2005.]

6. SCHILLER, Friedrich. A educação estética do homem. São Paulo: lluminuras, 1995. si em torno da questão do jogo e, todavia, se opõem enquanto sua dialetização não é iniciada por não ter sido planejada. Trata-se, por um lado, da mediação e, por outro, da estética. E do que está em jogo. Notemos que, se a instituição escolar é aqui mencionada antes das outras, todas elas estão envolvidas.

\section{RECALQUES}

\section{A mediação}

A instituição escolar não soube admitir que a língua, ao se tornar uma disciplina, não deixava de atravessar todas as outras disciplinas. Freqüentemente escutamos: "Eu não sou bom em francês", quando na verdade trata-se de outra coisa. Paralelamente, e ainda que toda mediação seja institucional, na escrita ela é mantida a distância devido a um ensino que não consegue se inscrever em uma abordagem comunicacional, quer dizer, em uma abordagem da linguagem que considera como suas as problemáticas do status do sujeito e do status do outro no uso da língua. Um pensamento comunicacional considera em particular a escrita como um fato de mediação, por oposição a uma prática individual ou singular de um sujeito. Ou seja, a escrita é pensada como espaço e tempo de enunciação, espaço e tempo nos quais se manifesta a relação do sujeito à sua experiência da linguagem, espaço e tempo nos quais, por conseqüência, se institui sua relação com o outro. Uma abordagem comunicacional obriga a teorizar a ausência do outro como constitutiva da escrita, por oposição à experiência da palavra.

Mas, por vezes, o que obriga ao mesmo tempo torna possível. É sem dúvida a razão pela qual a aprendizagem da escrita como mediação mantém um lugar preponderante nos dispositivos do que se nomeia inserção, não sendo possível evocar a necessária construção de um pertencimento consentido, mais do que suportado. A escrita como mediação é efetivamente própria para o sujeito tomar consciência de seu pertencimento; ela é necessária a toda consciência social.

Por outro lado, as representações e o ensino da escrita são marcados por uma antinomia, ainda mais perniciosa que implícita, entre as produções de textos que seriam concernentes à estética (a literatura, até mesmo a publicidade por via da retórica...) e aquelas que lhe seriam estranhas. A "segmentação do trabalho e da experiência sensível" , denunciada por Jacques Rancière e, antes dele, por Schiller nas suas cartas sobre A Educação Estética do Homem ${ }^{6}$, é assim perpetuada. Separando aqueles que criam daqueles que reproduzem, partilha do sensivel e partilha instituída das funções inscrevem-se no campo do político, enquanto representação e ensino se nutrem reciprocamente.

\section{A estética}

Vai-se, com a estética, da relação às formas que povoam o espaço da sociabilidade. Trata-se de percepção. Trata-se daquilo que, como real, atinge 
imediatamente o sujeito e o toca em seu corpo. O que se produz no curso da experiência estética é em parte da ordem do não-programado: da desordem. $\mathrm{O}$ sujeito inscreve seu desejo na percepção das formas significantes, isso de maneira tão singular como desprovida de intencionalidade. Maneira singular porque, do mesmo modo que o desejo, a experiência estética não seria da competência de uma identificação simbólica a outra: a especificidade da estética leva em conta o fato de que ela interroga a relação do sujeito com a forma, e não a ligação com outros sujeitos. Ela sobrevém no meio da experiência simbólica à qual transcende. E ainda é necessário sublinhar seu surgimento: o prazer estético escapa à vontade; não é passível de decisão. "Alguma coisa acontece de repente, não se sabe o quê: nem bonito, nem bom, nem verdadeiro, mas tudo isso ao mesmo tempo. Nem mesmo: outra coisa"7. O prazer estético escapa igualmente em parte às lógicas de interpretação e àquelas da sociabilidade. Ele coloca em perigo o contrato social, que se vê duplamente atacado. Em primeiro lugar, a confrontação do sujeito com a experiência de seu desejo suspende a sociabilidade; em segundo lugar, distanciado do curso da experiência sensível, o fato institucional é exposto à crítica.

Entender-se-á porque, para reduzir a parte que não é passível de decisão, foram instituídos lugares, tempos e práticas (teatros, museus, cinemas...). Nesses lugares que organizam, selecionam e limitam, a percepção estética é favorecida, encorajada, programada, "como se o espanto (assombro) abandonasse o domínio da existência cotidiana para ser, institucionalmente, recuperado" .

O medo de que o singular não escape ao controle social explica que a estética (própria da pessoa) seja freqüentemente confundida com a arte (institucionalmente reconhecida)? Trata-se do mesmo movimento que separa uma escrita que revelaria a arte, com letras maiúsculas, de outras, nomeadas a duras penas?

E, no entanto, já que no momento estético a forma se percebe e a linguagem se torna novamente uma matéria que o sentido tinha feito desaparecer, todo o emprego da língua é virtualmente próprio para dar lugar a uma experiência estética. Ela é virtualmente adequada para envolver o sujeito numa dupla relação com o significante: há o que o significante lhe faz, há o que ele faz ao significante. O trabalho do texto como aquele da fala coloca o sujeito, que precisamente trabalha a relação entre competência e performance, diante da estética.

Todavia, o processo de escrita, mais do que o da fala, favorece o encontro da matéria lingüística: "Falar afasta a percepção sensorial. A aquisição da linguagem a constrange, a recalca, a divide e a repele numa espécie de

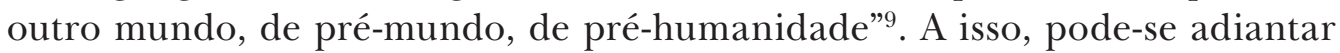
duas razões: a falta do outro e o espaço real, material, da página. Ao passo que, na fala, a realidade do espaço é determinada apenas pela presença do outro, presença que não pode ser recalcada, a escrita impõe esse recalque. E nesse espaço vago que a página vem ampliar, o olhar do sujeito da escrita se põe sobre uma palavra inscrita, distanciada de sua própria enunciação. A consistência real do significante, sem dúvida devido à falta do outro, é
7. GREIMAS, A.-J. De l'imperfection (Da imperfeição). Périgueux: Pierre Fanlac, 1987. p. 72-73.

8. DIDIER-WEILL, Alain. Les trois temps de la loi (Os três tempos da lei). Paris: Seuil, 1995. p. 14.

9. QUIGNARD, Pascal. Vie secrète (Vida secreta). Paris: Gallimard, 1998. p. 199. 
material e imediatamente sensível no espaço da página. O debruçar-se sobre o signo é favorecido e o arrepender-se, possível: "A palavra latina pagina significa o lugar mais vasto onde a alma possa se mover, viajar, comparar, voltar. É o pagus, o país"10. O trabalho do significante, que é suscetível de ser realizado, remete a produção do texto ao poético (poiein: fazer com as palavras).

Estética e poética fazem do processo de escrita uma experiência sensível e singular da linguagem, contrária às lógicas da transparência do signo e da instrumentalização da linguagem, e que coloca em ação a incompletude do significante.

A experiência da incompletude do significante remete ao arbitrário do signo. Ela remete ao momento em que o sujeito descobre que, decididamente, entre o significante e o significado não há um ajuste perfeito. Ele faz ao mesmo tempo a descoberta e a prova. Porque o sujeito, sempre sujeito social, não escapa; tratase de uma lei: a lei da incompletude. Sobre ela se funda a identidade.

Estética e poética suspendem a mediação e a identificação simbólica com o outro: trata-se de uma saída do espaço comunicacional. Não se pode estar, efetivamente, no mesmo instante, preocupado com a forma e com o outro. A preocupação com a forma provém da singularidade de uma experiência; aquela com o outro vem obliterar toda singularidade que possa fazer entrave à produção do sentido, da ordem do coletivo. Mas a identificação simbólica com o outro é substituída por uma identificação com o ideal de si, constitutivo, por outro lado, da experiência da arte.

Contudo, fora do campo da arte, seja na fala em nome da eficácia, seja na escrita em nome da legibilidade, a estética se vê recalcada por uma preocupação instrumentalista da linguagem, levada pela instituição encarregada de limitar o reconhecimento das formas à atribuição exclusiva de um significado, e de sempre reenviar o signo à sua dimensão de norma. Missão impossível que dá à lei toda sua dimensão.

\section{JOGOS DE ESCRITA: O RECALQUE DIVERTIDO?}

10. QUIGNARD, P. Sur le jadis (Sobre o tempo passado). Paris: Gallimard, 2002. p. 13.

11. YAGUELLO, Marina. Alice au pays du langage: pour comprendre la linguistique (Alice no país da linguagem: para compreender a lingüística). Paris: Seuil, 1981. p. 31

\section{Play, game}

Pode ser útil, antes de tratarmos dos jogos da escrita, evocar, como faz Marina Yaguello, em Alice no País da Linguagem, as duas orientações aparentemente contraditórias às quais remete o jogo:

[...] por um lado, a idéia de elasticidade, de liberdade, de margem, de movimento [eu acrescentaria: da estratégia], por outro lado a idéia de regra e de estrita união. É próprio do jogo conjugar a turbulência e a regra, a liberdade e a exigência ${ }^{11}$.

Não tendo como projeto estabelecer uma tipologia dos jogos da escrita, farei referência, todavia, a fim de caracterizá-los, à língua inglesa que dispõe 
de dois termos para se referir ao jogo ${ }^{12}$ : game, estritamente definido pelas regras que lhe dão curso, e play, do qual se pode falar de uma livre evolução, que não implica, entretanto, a ausência de todas as regras. É possível afirmar, de maneira talvez um pouco esquemática, que o essencial dos jogos da escrita, inspirados no trabalho da Oulipo (Oficina de literatura em potencial $)^{13}$, mesmo quando marcados pelo aleatório, corresponde ao primeiro termo. Ao segundo, pode-se associar práticas da escrita que dependem mais da expressão.

De modo geral, o jogo tem uma função importante na aprendizagem da vida coletiva e no processo de integração social. A priori, representa o prazer e a livre escolha: parece difícil obrigar alguém a jogar. $\mathrm{O}$ jogo possui uma dimensão iniciática no sentido de que é um meio - uma condição? - de formação cultural e social. A palavra iniciática evoca, aliás, a aprendizagem de uma vida coletiva.

Se a mudança da relação com o mundo e os diversos deslocamentos tornamse possíveis, nos jogos da escrita é nossa relação com a linguagem que se vê interrogada, deslocada. Ora, a relação com o mundo se manifesta na linguagem no ponto em que representações e palavra se identificam. E a palavra jogo tem ainda um outro sentido, o de representar um papel. Representações e palavras, atitudes e atos se articulam até se confundirem; essa confusão é o objetivo. $\mathrm{O}$ jogo, aqui, tem por função ou efeito a aprendizagem distanciada e crítica dos papéis sociais e das actanciais institucionais.

É, pois, no jogo, tenha ou não a palavra escrita por objeto, que se faz em parte a tomada de consciência da multiplicidade de nosso ser e que se constroem o sentimento da complexidade e a faculdade de duvidar, bem como aquela de viver na incerteza. Pelo jogo, o sujeito determina a distância: o olhar apreende de outra forma o que o jogo afasta, afastando-se. Modo de não ser mais, de recusar o compromisso, ou de mudá-lo. Isso significa que, como a porta, como a peça do motor, as quais têm certo jogo, a palavra escrita não é inteiramente presa em um mecanismo, pois desfruta de uma independência em relação à máquina ou aos sistemas aos quais pertence.

A atividade lúdica, enfim, necessita da interiorização das regras, nas quais o arbitrário permite igualmente a conscientização da gratuidade de certos compromissos nossos. Compreende-se que o jogo se transforma por vezes em práticas inquietantes em que o sujeito se fecha. Pergunta-se, então, se o game não está lá para manter distância da ameaça veiculada pelo play e se ele não foi inventado para que a atividade lúdica não escape ao controle social.

Para voltar aos jogos da escrita, eles tornam possíveis a experiência do significante e a da arbitrariedade do signo - prévia e necessariamente recalcadas pela aprendizagem da língua -, sem que a interrupção da relação com o outro, implicada por essa experiência, coloque a ordem em perigo. Pois, é necessário dizer novamente: a relação estética com a linguagem é da ordem do desejo ou do impulso, da ordem do real da pessoa, da ordem de uma
12. Em francês, a palavra "jeu" remete tanto a jogo quanto a brincadeira.

13. Oulipo - Ouvroir de Littérature Potentiel (Oficina de literatura em potencial) é uma corrente literária surgida na França na década de 1960 e formada, entre outros, por Ítalo Calvino. Propunha uma liberação da literatura através de regras assumidas pelos próprios autores, por exemplo, escrever todo um romance usando uma só vogal, ou escrever utilizando-se somente da linguagem oral. (N.E.) 
14. JAUSS, Hans Robert. Petite apologie de l'expérience esthétique. In: Id. Pour une esthétique de la réception (Pequena apologia da experiência estética. Por uma estética da recepção). Trad. fr. de Claude Maillard. Paris: Gallimard, 1978. p. 136.

15. KANT, Immanuel. Critique de la faculté de juger (Crítica à faculdade de julgar). Paris: Gallimard, 1975. § 43, p. 258. apropriação singular. Ela faz do momento em que toma o sujeito um instante de suspensão da troca. É um momento no curso do qual o sujeito se encontra sozinho, sem relação com o outro, na perda de sua presença como elemento de relação de identificação especular constitutiva de sua identidade. Momento de ruptura, de estupefação por vezes, no continuum da relação com o outro. Mas, tanto na instituição escolar como nos dispositivos de formação, esses jogos são praticados em grupo e em uma alternância de tempo de escrita, pela necessidade individual, e de tempo propriamente dito, de socialização, ou seja, de leitura coletiva.

É fundamental que essa experiência torne-se possível: não se pode pensar a escrita fora de um trabalho do significante que se permita à apropriação. Ora, somente a consciência da materialidade do signo pelo sujeito é adequada para lhe fazer aceder ao desejo da língua, essa instituição primeira, portadora de leis e de normas. A descoberta e o reconhecimento do significante e de sua opacidade vêm, além disso, perturbar a ilusão perniciosa da transparência da linguagem, ou de sua possível neutralidade.

Em seguida, da mesma maneira que em outros jogos, certos jogos de escrita obrigam à marcação, à tomada de lugar ou de distância, ao deslocamento das identidades enunciativas. O distanciamento entre o sujeito e o texto vem trabalhar a distância representativa. Fundada pelo corte semiótico, remetendo à incompletude do significante, a distância representativa nos lembra de que a representação se interpõe entre o nós e o real. Distância sem a qual não há cultura pensável, ela se opõe aos mitos da própria presença e do imediatismo das relações sociais. A escrita é o lugar privilegiado de tal experiência: pelo gesto da mão, ela obriga a um distanciamento de nossos próprios papéis, que permite o retorno crítico necessário à representação, por ela mesma, da verdade do sujeito.

Da mesma maneira que em outros, nos jogos de escrita, a prática vem se articular a um desejo. E aqui se descobre, porque se desloca, o que está em jogo no ato da escrita. Não é mais a norma, não é mais o risco social que fazem o jogo: é o prazer que se saberá achar, a não ser que se fracasse. Que se saberá achá-lo, caso se chegue a ele.

"Em uma sociedade que ainda fundamenta, a despeito de uma secularização total, a moral pública e o prestígio social sobre a oposição entre o trabalho e o deleite" ${ }^{\prime \prime}$, as pedagogias da escrita, que não tornam possível a experiência da escrita como dialetização entre criação e razão, sustentam esta oposição, em meu ponto de vista, perniciosa. Essa dialetização pode, entretanto, ser objeto de uma aprendizagem. Mas Kant já havia notado:

[...] um bom número de novos educadores imaginam contribuir da melhor maneira para uma arte liberal, enquanto eles a livram de todas as exigências e, do trabalho que ela era na origem, transformam-na em um simples jogo ${ }^{15}$.

Nós indicaremos então os limites. 


\section{... e circenses, ou: "que os jogos não sejam feitos, que exista o jogo"116}

Terminados os jogos de escrita, o que fazer agora? Não são eles elaborados gratuitamente para distrair e se distanciar daquilo que importa? Alguns, se colocando ao lado do play e da expressã $0^{17}$, não incitariam o refúgio atrás da ilusão de uma escrita como palavra individual, livre, criativa e espontânea, eventualmente nutrida de uma segunda ilusão, mais psicologista ainda: a de uma unidade da linguagem e do sujeito? A outros, não lhes fazem correr o risco de esquecer que a língua é instituição, e a instituição é "único e magistral meio de exclusão"18, e que entretanto o código garante a liberdade do sujeito? E que a aprendizagem tem por missão evitar esses riscos? Não os fazem correr um último risco: aquele do refúgio poético de um sujeito só e perdido na contemplação de si mesmo? Tudo lhes deixando crer que atingem à arte.

Nos estágios de inserção, tive ocasião de escutar, de ver, pessoas exprimirem ressentimento e frustração por ser mantidas fechadas em um espaço de prazer obrigatório, em que a norma é suprimida e a subversão, permitida; ao mesmo tempo em que mantidas em sua incapacidade, para se conformarem com os modelos impostos, sem o conhecimento dos quais ninguém atinge um status de ator social. Ressentimento e frustração, de ser pego em clivagem.

A posição de partida desses dispositivos não é formulada, tanto que ela parece evidente: imposição de se escrever como se fala e de não se preocupar com a ortografia, silêncio quanto aos objetivos e àquilo que está em jogo, medo de abordar a reescrita; ou seja, nada menos do que a produção do texto como trabalho. Tudo isso se observa, sem que a questão seja ao menos colocada.

Os participantes mais autônomos o pressentem: a experiência da escrita, como aprendizagem de um trabalho e interiorização de normas, funda uma experiência social e institucional da mediação que lhes faz falta. O que a escola, com eles, errou, não deve certamente ser reproduzido. Dessa vez, eles querem se apropriar do código. Querem ter acesso à escrita em toda sua dimensão, ou seja, aquela de uma prática simbólica cuja apropriação passa de maneira incontornável por uma submissão consentida à norma, e onde se nota que, dessa vez, eles compreenderam a relação com o outro.

Os outros: para eles o tempo passa, um pouco de outra maneira, apenas menos perdido. E isto é tudo.

É necessário saber: não é tanto o pão que falta, nem o circo, aliás, mas a faculdade de se ter acesso enquanto sujeito.

O sentimento de vazio que, a justo título, diversos jogos e ateliês de escrita proporcionam, explica a desconsideração de que eles são vítimas. Mas o divertimento pascalino (relativo a Pascal) já não representava o conjunto de estratégias que visam ao esquecimento de si e da "infelicidade natural de nossa condição falível e mortal, tão miserável"19?
16. BARTHES, op. cit., p. 1496.

17. Em latim, expremere significa "fazer sair com urgência, rapidez" (faire sortir en pressant). (N.E.)

18. LEGENDRE, Pierre. L'amour du censeur: essai sur l'ordre dogmatique (O amor do censor: ensaio sobre a ordem dogmática). Paris: Seuil, 1974. p. 44.

19. Do original: "malheur naturel de notre condition faible et mortelle, et si misérable". PASCAL, Blaise. Pensées. 1670: 1-433. [Ed. bras.: Pensamentos. São Paulo: Martin Claret, 2003.] Pensées et opuscules (Pensamentos e opúsculos). Paris: Le club français du livre, 1957. p. 232 
comunicação \& educação • Ano XIII • Número 1 • jan/abr 2008

\section{A MEDIAÇÃO ESTÉTICA}

Há esquecimentos que levam à perda de nossa identidade e à impossibilidade de nos reconhecermos e nos assumirmos como sujeitos livres. A mediação estética, enquanto tal, inscrevendo o sujeito na dimensão coletiva e cultural da norma estética, o reenvia a seu lugar de pertencimento, cada um estabelecendo uma mediação entre sua própria experiência, nutrido de um desejo singular, e o fato de que a língua é algo coletivo.

Se, efetivamente, a percepção e, mais ainda, a emoção são da ordem do singular, o signo remete inevitavelmente ao coletivo: é na dialetização entre um e outro, entre o singular da estética e o coletivo da semiótica, que acontece a mediação.

A mediação estética, quando experimentada fora do campo da arte, tem algo de clandestino. Ela consiste em uma apropriação (no sentido de onde se apropria) simbólica do sujeito sobre o real. Ela consiste em uma aptidão para se retirar, para se colocar de lado, em uma prática solitária e imprevisível das formas. Trata-se de uma aptidão para tentar, indefinidamente, reencontrar o assombro da ruptura. "Já que o prazer e a pena estão necessariamente ligados à faculdade de desejar" ${ }^{\circ}$, ela é o deslocamento do desejo em direção à maior apropriação: apropriação do desejo $e$ da ausência. A mediação estética é uma faculdade intermediária do espírito humano, ou uma capacidade para tomar para si o real e suas formas, e isto fora de qualquer espaço ou de qualquer tempo instituído para tais fins.

Mas da mesma forma, dessa vez no campo da arte, nesse movimento em que desejo e ausência se põem à prova, o sujeito é confrontado com o ideal de si. O que ele carrega de inadequação entre imaginação e razão faz do ideal de si um horizonte, por natureza, inacessível. E a busca subsiste, aquela que funda o desejo da ausência. Desejo do devir, o desejo da ausência não saberia se aplicar a um objeto real: o sujeito inscreve a consistência que o funda como sujeito simbólico, ao mesmo tempo que o distingue de outros. Ele procede à elucidação daquilo que sustenta nele de verdadeiro e faz a descoberta sempre renovada de que não é um, exceto no instante.

A identificação com o ideal de si mesmo envolve o sujeito da escrita em um trabalho de dialetização entre desejo e lei, singularidade e pertencimento, que faz a escrita obter seu status de mediação estética da sociabilidade e a torna plenamente significante.

Fala-se de palavra plena para evocar uma palavra que é, além de toda a intencionalidade e dentro de uma identidade da qual ela fala. Assim, a escrita plena não serve para comunicar. Embrião entre saber e desejo, é uma maneira de pensar o significante no presente do próprio ser, e seu engajamento nesse presente.

O saber, permitindo ao sujeito generalizar sua experiência singular, religa-o tique de la faculté de juger (Crítica à faculdade de julgar). Trad. fr. dirigée par Ferdinand Alquié Paris: Gallimard, 1985. p. 104. aos outros e o inscreve na sociabilidade. Quando o saber se liga ao desejo, o sujeito tem toda certeza daquela sua existência, na medida em que sua escrita, ou sua palavra, a cria. 
Os jogos de escrita, game ou play - e é bom, sem dúvida, que eles sejam alternativamente um e outro - têm motivo para surpreender aquele que os observa serem realizados: no prazer do gesto que apreende o significante, eles abrem para a experiência do sentido e da identidade. E, estranhamente, isto é visível. Eles não serão, entretanto, mais do que abertura de um espaço, que imediatamente se fecha, se mais adiante a instituição que os instaura exclui o desejo do significante da produção das formas ordinárias da sociabilidade pela qual se inventa o cotidiano.

Resumo: Discute-se a linguagem verbal como campo estruturado e renovável, que se distingue por revelar competências e performance dos falantes de uma língua, abrindo-Ihes espaço para infindáveis possibilidades e fundando a instância do sujeito. A escola institui o aprendizado da escrita da norma-padrão e esquece que a língua atravessa todos os campos do saber, inclusive o da estética. E é a experiência estética, principalmente com a escrita da língua, que oferece ao sujeito a consciência da sua singularidade.

Palavras-chave: linguagem escrita, fala, estética, jogo, sujeito.
Abstract: It discusses the verbal language as a structured and renewable field that is distinguished for revealing competences and performance of the speakers of a language, opening spaces for boundless possibilities and founding the instance of the subject. School institutes the learning of the standard writing rules and forgets that language crosses all fields of knowledge, including the one of aesthetics. It is the aesthetic experience, mainly with the language writing, that offers to the subject the conscience of his singularity.

Keyword: written language, speech, aesthetics, game, subject. 


\section{A FAMÍLIA, DE NOVO, NO CENTRO DAS ATENÇÕES!}

Considerada hoje um dos maiores recursos de sustentação para a pessoa e a sociedade, a família retoma lugar de destaque no meio acadêmico-científico, de onde esteve ausente durante anos. Um silêncio eloqüente nos ambientes universitários parecia caucionar certo posicionamento de que estaria em vias de extinção. Mas, mesmo afetada por mudanças socioculturais, éticas e religiosas, ela reage - e se adapta - a condicionamentos externos, encontrando novas formas de organização que a reconstituem.

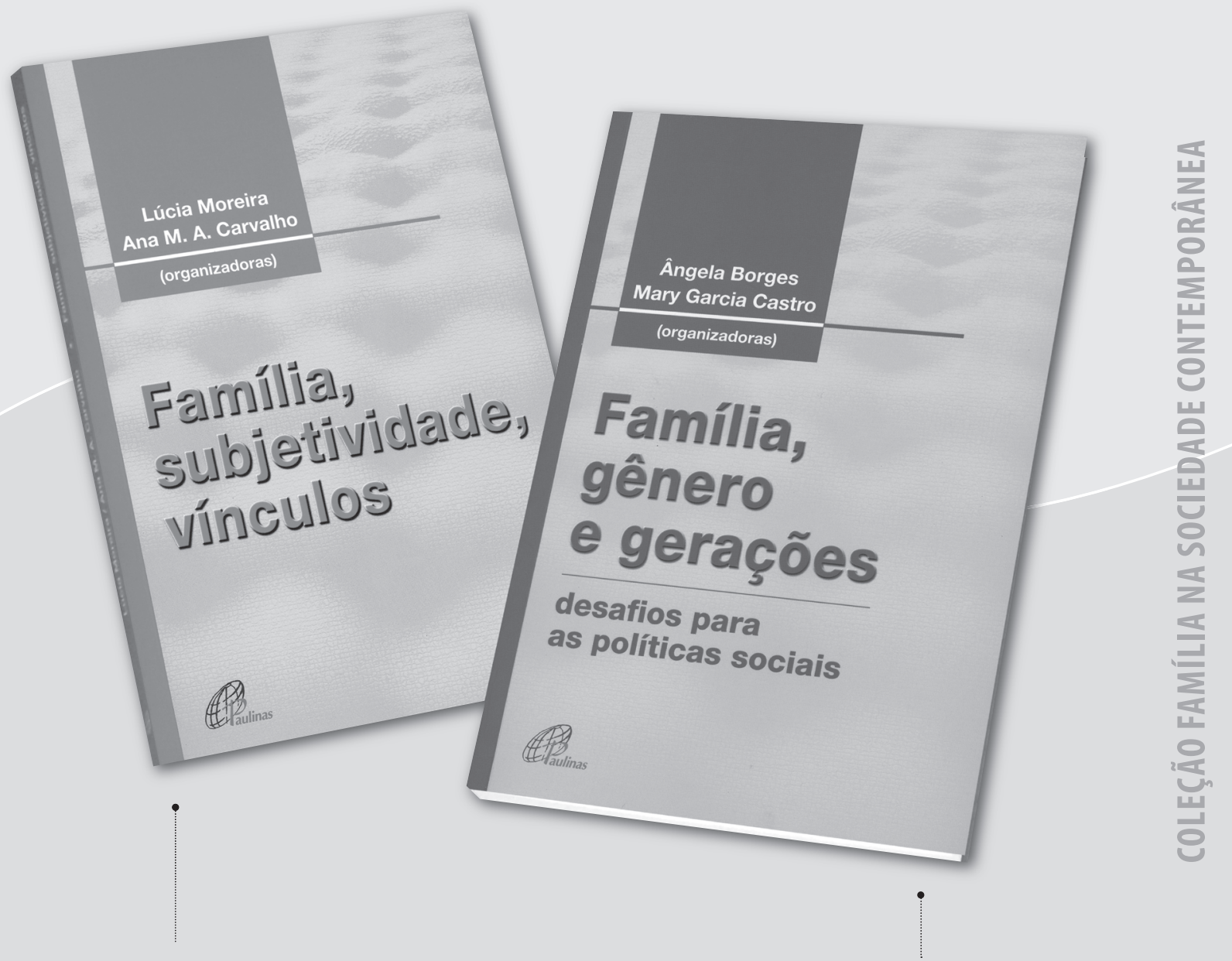

FAMÍLIA, SUBJETIVIDADE, VÍNCULOS

Orgs.: Lúcia Vaz de Campos Moreira e Ana M. A. Carvalho

Páginas: 216| ISBN: 9788535619706

Este livro quer contribuir com a ampliação do debate multidisciplinar sobre as razões da existência da família, as suas formas de organização, as mudanças que a influenciam, seus conflitos e tensões e o futuro que a espera. Complexo, 0 assunto é tratado com clareza tanto para especialistas quanto para os que querem compreender melhor a realidade da família na atualidade.
FAMÍLIA, GÊNERO E GERAÇÕES

Orgs.: Ângela Borges e Mary Garcia Castro

Páginas: 232 | ISBN: 9788535620900

Para resgatar 0 valor público do núcleo familiar, especialistas lançam bases para uma ação em prol da família, por parte da sociedade civil e do Estado. Seus artigos tratam, sob várias perspectivas, das transformações em curso nas famílias e suas manifestações, destacando interações entre gerações e gêneros. Entre os muitos temas, enfocam juventude e sexualidade, envelhecimento, contribuição das mulheres e divisão sexual do trabalho doméstico não remunerado. 